\title{
Why Should We Make Low -Cost Eco-Friendly Chalks? Bangladesh Perspective
}

\author{
M. A. H. Mithu*1, T. Akther ${ }^{2}$, M. R. Ahmed ${ }^{2}$ and B. Morshed ${ }^{2}$ \\ Professor, Department of Industrial \& Production Engineering, \\ Shahjalal University of Science \& Technology, Sylhet, Bangladesh ${ }^{1}$ \\ Undergraduate Student, Department of Industrial \& Production Engineering, \\ Shahjalal University of Science \& Technology, Sylhet, Bangladesh ${ }^{2}$
}

\begin{abstract}
Traditional blackboard chalk is still a prevalent teaching medium especially in most of the primary and secondary schools in the developing countries. These chalks not only pollute the classroom environments but also cause a high prevalence of chalk dust problems among teachers and young students. This article aims to identify the effects of traditional chalk dusts and to design and fabricate eco-friendly chalks. To fulfil these objectives, a cross-sectional study was carried out between October 2013 to January 2014 with a sample of 290 teachers, students and guardians in Sylhet division, Bangladesh and analyzed. The fabrication criterion of eco-friendly chalk was designed based on the identified customer requirements. Different health-related problems due to chalk dust are also identified. It is found that these fine particles of chalk dust in the classroom can exert some adverse effects on the human respiratory system, eye, skin, and hair etc. A series of lab tests and field studies were carried out to assess the performance of the fabricated chalk. The fabricated dustless chalk having a tapered cylindrical shape with a specified length and diameter offers many advantages over the traditional chalk in terms of flexibility, color, visibility, price, ease of use, etc.
\end{abstract}

Keywords: Blackboard chalk; Chalk dust; Chalk performance; Eco-friendly environment; Health hazards

\section{INTRODUCTION}

Blackboard chalk is being used as a teaching medium for a long time in the developed, developing, and underdeveloped countries since ancient age. However, the blackboard chalk became commonly accessible as a teaching medium in the classroom when class size increased at the beginning of the 19th century as the teachers wanted to get a means to convey useful information to many more students at once [1]. Many studies [2-5] have demonstrated that a chalkboard is a useful tool for classroom teaching along with various advantages such as the use of chalk is inexpensive, easy to clean and reuse, universal access and recognition, available colors, made of almost non-toxic substances, and most importantly it allows students to keep pace with the teacher where the students can remarkably stay more attentive than mere speech mode of demonstration, and is not dependent on electricity, compared to other teaching aids. However, the blackboard chalk is scraped across the rough surface which produces very fine particles of chalk dust. These chalk dusts settled down the blackboard or dispersed into the surrounding air of the classroom. These dusts remain suspended in the air for a short time before settling down the blackboard and later on the floor and body parts such as hands, shoulders, eyes, or enter the respiratory tracts of the teachers and pupils; and even enter the electronic equipment placed in the classroom [6].

The traditional blackboard chalk is a soft, slender stick approximately 0.35 inch $(9.0 \mathrm{~mm})$ in diameter and 3.15 inches $(80 \mathrm{~mm})$ long, made of from purified fine grains of limestone Calcium Carbonate $\left(\mathrm{CaCO}_{2}\right)$ and/or Gypsum $\left(\mathrm{CaSO}_{4} \cdot 2 \mathrm{H}_{2} \mathrm{O}\right)$, mixes with water, binder and pigments are added if necessary, baked in a mold, dehydrated, and become ready to use. So, it is generally considered to be non-toxic, when exposed to a shorter period. However, among the ingredients of chalk composition, some metallic elements like lead, manganese, barium remain even at a deficient percentage and a high content of the metal cadmium exits. These heavy metals are poisonous to the body as they are not metabolized or excreted and ultimately accumulate in organs and tissues [7, 8]. If cadmium is inhaled, an early manifestation of weakness, lean, dizziness, loss of appetite and symptoms of neurasthenia, and nasal bleeding, chronic pharyngitis, nasal mucosa atrophy, and ulcers are more common, and long-term exposure to cadmium compounds gradually damages the kidney, liver and bone tissue [9-11]. Teachers devote approximately 6 to 8 hour each teaching day, and the young scholars spent at least one-third of their day in the classroom. Teachers are mostly sufferer the chalk dust since they are exposed to it over a long period, sometimes 30 years or more [12]. Thus, it is not surprising that fine chalk dust in the classroom can exert some adverse effects on the human respiratory system, affects lachrymal gland excretion, tears hydrolysis, also lead to severe acne, felicitis, pyoderma, skin chap and a lot of hair drops, influence, and trouble the teacher normal operation and livelihood. Among the problems, lung inflammation is central to the 


\title{
International Advanced Research Journal in Science, Engineering and Technology
}

\author{
Vol. 6, Issue 11, November 2019
}

pathogenesis of airway disorders, including acute lung injury, abdominal pain, chronic obstructive pulmonary disease, chronic bronchitis, and asthma [13-15]. The American Academy of Allergy, Asthma \& Immunology documented that the chalks are mostly used in the schools or colleges, and the teachers have the greatest direct risk associated with chalk dust as they enter the respiratory system through nasopharyngeal region and mouth due to their proximity to the board and frequent opening of mouth during lectures, and occasional gasping and heavier breathing due to exhaustion in the dusty environment [16]. As a result, teachers and younger students may suffer from various respiratory and allergic problems due to the dusty environment. A study conducted in Kenya shows that there is an association between teaching occupation and allergic conjunctivitis with teachers having a prevalence of 52\% [17, 18]. Nikam and Munira [19] confirmed that teachers using chalk and board are at an increased risk of developing occupationally related pulmonary function impairments.

Bangladesh has 18 million children in 62,000 primary schools. It is considered as one of the largest primary systems in the world. Over $65 \%$ of the primary schools are government primary schools, and the rest are registered nongovernmental schools but assisted by the government. There is also an enormous number of private schools, but, the number of students enrolled in private schools is much fewer, and these schools mostly cater to social elites. According to Education Statistics 2012-2018, the government of Bangladesh distributes free books and education kits to the students of primary schools. About 98 percent of total funding on education are now spending on different sectors like the distribution of free books, teachers' remuneration, teachers' upgradation training, administration, and classroom equipment. This leaves a tiny percentage for operational expenditure. Allocation of total expenditure on classroom equipment is not enough to convert from a traditional classroom to a modern room. Therefore, most of the governmental institutions use chalk-board as a teaching medium due to inadequate investment on annual operational expenditure and maintenance budget. The government schools are still provided chalk yet modern technologies like a white-board marker and multimedia projector had been launched in the market. As a result, teachers and younger students must go through a dusty teaching environment and sometimes suffer from various health-related problems. Some of the good quality dustless chalks using across institutes are imported from foreign countries, but these are less commonly used in developing countries like Bangladesh. However, dustless chalk also produces dust, but the dust is heavy because of the compressing of the chalk. These dust particles fall vertical and near to the board instead of flying around the place while writing and erasing. This dust settles faster than that of the traditional dusty chalk [20]. A big percentage of these traditional chalk dusts enter in the mucus layers of the throat and upper lungs causing respiratory symptoms such as coughing, wheezing, shortness of breath, and nasal symptoms such as sneezing or congestion and asthmatic attacks [20-22]. Most cases the occupational diseases are never diagnosed and/or reported as well. Very often, signs and symptoms related to occupational exposure, result in several occupational diseases. Lin [12] showed that approximately $15 \%$ of observed chalk dust particles are respirable and high concentrations of chalk dust deteriorated the indoor air quality. The mechanical ventilation resuspended the settled chalk dust particles, thereby increasing the mass concentration of airborne dust. The problem becomes more significant when the chalk becomes colorful. Hung [23] conducted research on the legibility of different colored chalk on a blackboard and showed that the colorful chalks are created by mixing calcium compounds at least $80 \%$ and dyes. These colorful chalks are profoundly more severe than white calcium compound ingredients. Moreover, allergic conjunctivitis is associated with itchy eyes and nose sneezing which may make the teacher concentrate on the rubbing of the eyes \& cleaning nose interfering while delivering a speech [24-26]. From the works of literature, it is found that the chalk-board is a useful aid for classroom teaching with numerous advantages in the sense of expenditure, cleanness and reuse, available colors, and it offers a powerful communicative tool between teacher and student. Despite different advantages, the dust produces the teaching environment unhealthy for both teachers and young students, particularly in school levels. Airborne dust gradually promotes occupational exposure. This research is, therefore, carried out to find out the adverse effect of the dusty environment and to provide a healthy and dust-free classroom environment so that teachers and students can work in a safe atmosphere. This study focuses on:

i. find out who the victims are, in what percentage,

ii. what types of health hazards usually occur, and

iii. fabrication of eco-friendly chalk which would be safe to human health \& keep the environment clean \& green.

\section{METHODOLOGY}

The research is divided into three folds such as (i) a comparative survey, which finds the number of victims and related health hazards, (ii) fabrication of the blackboard chalk based on the survey results, and (iii) a series of field study to characterize the fabricated chalk. A questionnaire was prepared to identify the problems usually caused using traditional chalk and to find out the customers' requirements. Then based on the customers' requirements, some dustless chalks were fabricated. An optimum combination of main ingredients, binder, and water was identified as such the fabricated chalk produced minimum dust. A series of field studies were performed to test visibility, erasability, consumption, and the amount of dust, the tendency of breakage, and the provision of features that can be provided at a reasonable cost. 


\section{International Advanced Research Journal in Science, Engineering and Technology}

Vol. 6, Issue 11, November 2019

\subsection{Comparative study}

The study area was limited to the Sylhet district in Bangladesh, which covers the maximum number of educational institutes and it was carried out between October 2013 to January 2014 with a sample of 290 teachers, students, and guardians in Sylhet division. The study was restricted to a range for its easy access, coordination, administration, and ease of supervision. There are six universities, 31 colleges, 56 high schools, and a considerable number of primary schools in Sylhet district. People, who use chalk in their profession or may meet chalk, i.e., teacher, student, and tailor are in inclusion criteria. But this research considers only the people associated with the educational institutes. Teachers use chalk, and students also come in contact with chalk dust as it spread all over the classroom while cleaning the board. However, English medium schools, private universities, coaching centers, tutor home, training center were excluded from this research.

In the comparative study, the target population was the teachers of all levels, from primary school to university, students of primary schools, high schools and colleges, and guardians. Therefore, the study population was the teachers of state-owned institutes, students of all levels, and some guardians in the Sylhet division. Guardians were considered as the representative of the students of primary level who usually were not able to answer on a written questionnaire. Closed questionnaires were collected, organized, coded, and entered into the database for analysis. The SPSS ${ }^{\circledR} 20$ (Statistical Package for the Social Sciences) packages were used to construct the database. The SPSS ${ }^{\circledR} 20$ and Microsoft Excel $^{\circledR} 2013$ were used to analyze the data.

\subsection{Fabrication of chalk}

The fabrication of chalk included the selection of raw materials, design of the product and the sequence of processing operations through which the product would be fabricated. Primary raw materials were calcium carbonate $\left(\mathrm{CaCO}_{3}\right)$, calcium sulfate $\left(\mathrm{CaSO}_{4}\right)$ and binder. Three types of commercial adhesives- synthetic resin binder, paper gum, and synthetic adhesive binder were used as binders.

The designed mold, shown in figure 1, consisted of three half-circle drilled wooden plate coupled together by nut and bolts. Five of the ten mold cavities were cylindrical $(\varnothing, 9 \mathrm{~mm})$ and the rest were tapered $(\varnothing 1,10 \mathrm{~mm}$ and $\varnothing 2,8 \mathrm{~mm})$ to fabricate tapered chalk. The mold was placed on a rectangular grooved wooden base to mount the three parts accurately on every setup.

Limestone (or gypsum) was first crushed, conveyed to vibrating screens that sifted out the finer material, which was then washed to remove impurities, leaving behind a fine powder and dried. Fix the amount of water, and binder added to form a thick slurry which was then poured into designed mold cavities. The filled-up wooden mold was placed in an oven, where the chalk cures for predefined temperature. After curing, the stick formed chalks were brought out of the mold separating the wooden box.

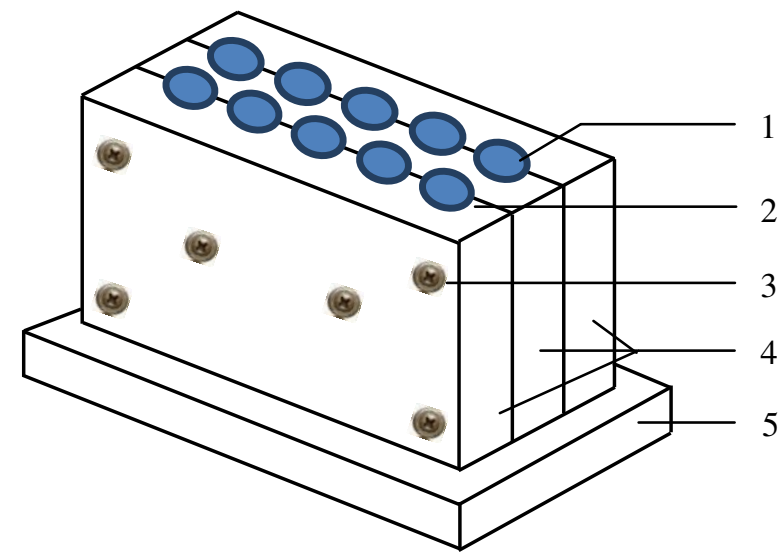

Fig. 1 Fabricated mold consists of three half-circle drilled wooden plate joined by screws;

1. Tapered mold cavity $\left(\emptyset_{1}, 10 \mathrm{~mm} ; \emptyset_{2}, 8 \mathrm{~mm}\right)$;

2. Cylindrical mold cavity $(\varnothing, 9 \mathrm{~mm})$;

3. Joining screw;

4. Wooden mold frame; and

5. Wooden baseplate.

\subsection{Field study}

A series of experimental works were carried out to check the attributes of the proposed eco-chalk.

Visibility: Visibility of chalk mark on board is a predominant feature. A simple device made of wood was used so that it can exert the same amount of force throughout the line for every specimen. In this experiment, 18 different categories of chalks with different percentage of ingredients were prepared. These fabricated chalks were ranked on 5 Likert 


\section{International Advanced Research Journal in Science, Engineering and Technology}

Vol. 6, Issue 11, November 2019

scales, where 5 for very good and 1 for very bad, and so on. These prepared chalks were graded based on their visibility.

Erasability: Like the visibility test, the same scale was used to grade the chalk based on its erasability. In this test, the chalks exhibited utmost visibility were selected.

Dust content: The dust measuring test is one type of comparative test. It was done for the chalks selected from the previous tests. During writing and cleaning, the same force was maintained all over the path. For measuring the dust contents, the same scale was used where 1 for very high content and 5 for very low contents, i.e., the most dust producing chalk had the least value and vice versa. The chalks which created either the same amount or more as compared to standard chalk were eliminated for the next step. The less dust-producing chalks was the expected outcome of our experiment.

Microstructure: After leaving a mark on the board, a digital microscope was set upon the mark. Then focusing on a specified area, images were captured and saved in a computer. Microscopic views of the captured areas were scrutinized by the commercial software Measurement ${ }^{\circledR}$ to observe the mark-density as well as visibility of the chalk.

Attribute test: The chalks which showed the best performance in lab test were selected for the attribute test. These selected chalks were assessed based on their attributes like visibility, erasability, dust, and consumption. The sample was evaluated by the students of Industrial and Production Engineering Department of Shahjalal University of Science \& Technology, Sylhet. Before the attribute test, the weight of each preselected chalk was measured by digital weight machine. After the field test, the weight of the chalk was measured. The consumption rate of each chalk was computed by subtracting the later measurement from the former one.

\section{RESULTS}

\subsection{Comparative study}

Among the expected population of 1180, the study sample consisted of a total of 290 respondents with a confidence level of $95 \%$ was taken, in which 204 teachers, 58 students, and 28 guardians. In terms of gender, there are 67 male teachers and 137 female teachers, 25 male students, and 33 female students and 19 female guardians and nine male guardians. From the Fig. 2, it is observed that among 204 teachers, most of the teachers (61.76\%) practice only chalk as their teaching medium, $13.24 \%$ of the teachers use only whiteboard maker, and $15.69 \%$ of the teachers use both traditional chalk and a whiteboard marker. A tiny percentage of teachers $(0.98 \%)$ use the multimedia projector for teaching purpose. The analysis also shows that about $87 \%$ of primary school teachers and $63.1 \%$ of high school teachers use only chalk as a teaching medium. Moreover, among the chalk users, about $12.7 \%$ male and $87.3 \%$ female in primary schools; $45.3 \%$ male and $54.7 \%$ female in secondary schools; $40 \%$ male and $60 \%$ female in colleges, $50 \%$ male and $50 \%$ female in universities use traditional chalks in the classroom for teaching purpose.

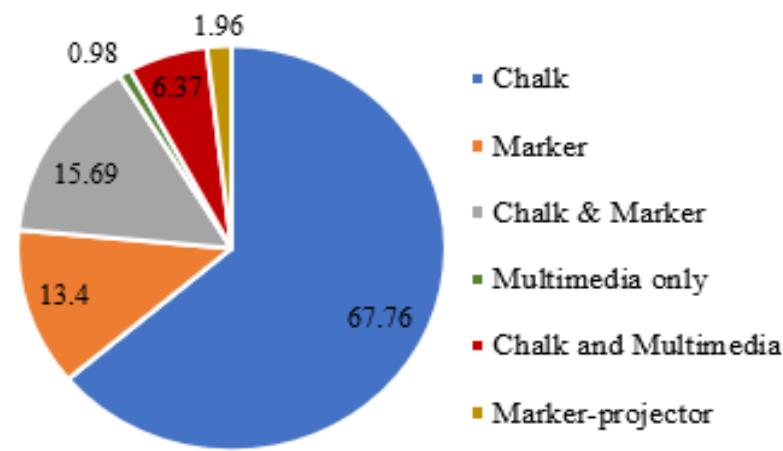

Fig. 2 Medium of teaching aids used by educators during teaching.

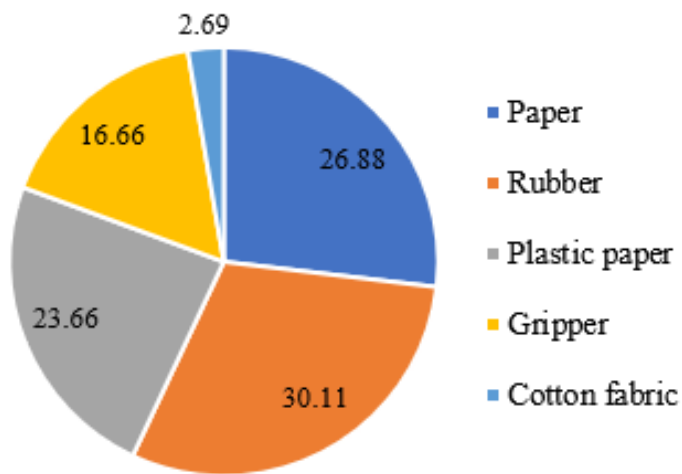

Fig. 3 Preference on covered chalk by materials. 


\section{International Advanced Research Journal in Science, Engineering and Technology}

Vol. 6, Issue 11, November 2019

Fig. 3 depicts that among the chalkboard users, 91.2\% of users have a positive response to having a cover on chalk, where preference on paper, rubber, plastic paper, gripper and cotton fabric as cover are $26.88 \%, 30.11 \%, 23.66 \%$, $16.67 \%$, and $2.69 \%$ respectively. Majority of the respondents have a preference on chalk colors. In response to the question, 'Which color of the chalk do you prefer to white color? $L$ Green, $\lrcorner$ Yellow, $\lrcorner$ Orange, $\lrcorner$ Carmine red, $L$ Pink, $\lrcorner$ Other: (Please specify)'. It is found that $25.2 \%, 6.2 \%, 9.3 \%, 22.4 \%$, and $36.9 \%$ of the respondents had chosen green, yellow, orange, and carmine red, and pink color, respectively. A distinct difference in color preference is found in yellow and pink color. $11.1 \%$ male teacher, $66.7 \%$ female teacher, and $22.2 \%$ students prefer yellow color; and $21 \%$ male teacher, $51 \%$ female teacher, and $28 \%$ students prefer pink color, as depicted in Fig. 4 . The number of males and females are not identified in the case of students.
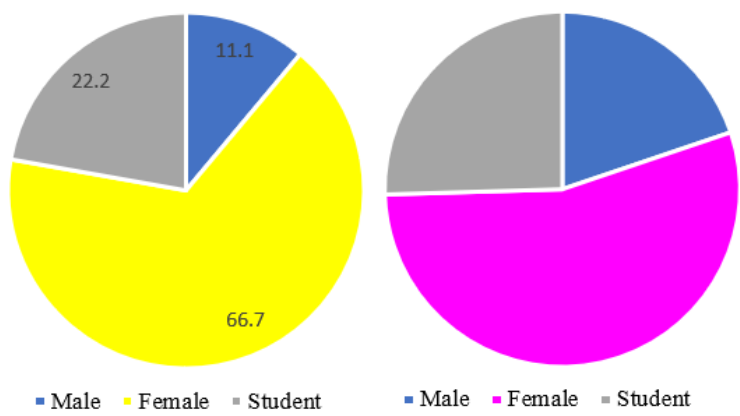

Fig. 4 Preference on chalk color other than white; preference on the yellow color (left side) and preference on the pink color (right side).

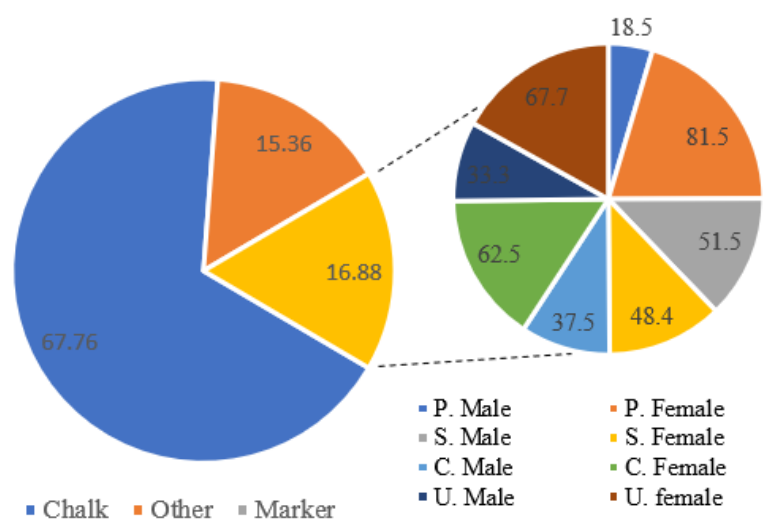

Fig. 5 Preference on marker users other than chalk.

From Fig. 5, it is apparent that among the whiteboard marker users, about $18.5 \%$ male and $81.5 \%$ female in primary schools, $51.6 \%$ male and $48.4 \%$ female in secondary schools, $37.5 \%$ male and $62.5 \%$ female in colleges, $33.3 \%$ male and $66.7 \%$ female in universities are using whiteboard marker as a teaching aid in the classroom. As shown in the figure, preference on the marker nib shape is also evident. Among the whiteboard marker users, $63.69 \%$ and $36.31 \%$ prefer round-shaped and chisel-shaped nibs, respectively.

\subsection{Health hazards}

It is apparent that about 51 percent of the students do not share the health problems to their parents. Majority of the male students share to their parents whereas only 32 female students share it to their parents. The guardians (28) are asked how frequently they talk with their child about the health problems she/he was facing at school. The answer was for rare (10.7\%), sometimes (71.4\%), frequent (10.7\%) and always (7.2). The result also has shown that about $82.14 \%$ (23 out of 28) guardians discuss their children's health problems with school teacher once in every six months. The percentage of guardians who are discussing in every week, every month, once per six months and once per year were $8.69 \%, 8.69 \%, 60.86 \%$, and $17.85 \%$, respectively. The guardians were asked whether authority took necessary steps when students faced any health problems; the answer was positive, and the value is $78.6 \%$. Some of the guardians provided primary treatment, and most of them consulted a doctor when their children got sick, and the values are $35.7 \%$ and $64.3 \%$, respectively. According to Fig. 6, among the 290 people, $91.7 \%$ claims that they have faced different types of health-related problems. Among the health-related problems, various allergy problems, respiratory system related problems, eye-related problems, skin related problem, and hair related problems are most common, and the values are 


\section{International Advanced Research Journal in Science, Engineering and Technology}

Vol. 6, Issue 11, November 2019

$65.8 \%, 65.8 \%, 79.3 \%, 86.5 \%, 81.2 \%$, respectively. Among the allergy problems, $71.7 \%$ are teachers and the rest are students, and among the allergy-related sufferers, $75 \%$ encountered allergic conjunctivitis.

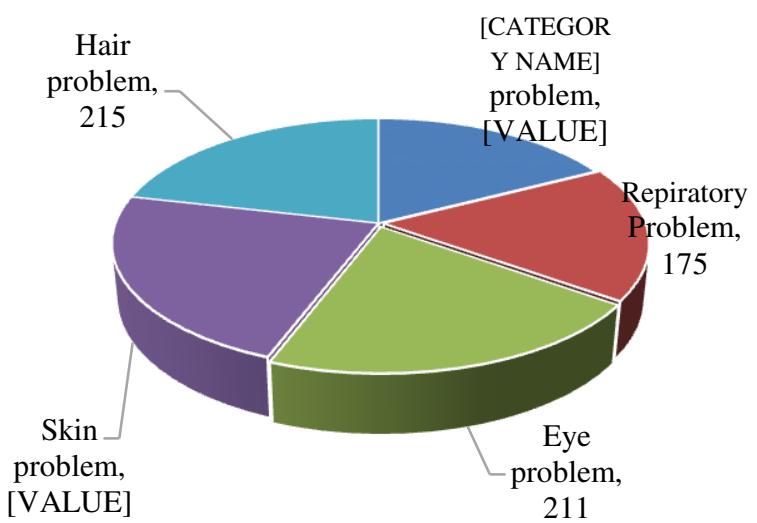

Fig. 6 Percentage of respondents have faced different types of health-related problems.

Among the respondents who are suffering from respiratory problems, the ratio of the teacher and student are $68.3 \%$ and $31.7 \%$, respectively. The result of the percentage of sufferers from different types of respiratory-related and eye-related problems are summarized in Fig. 7 and Fig. 8, respectively. Among 290 respondents, around 97\% respondents claim eye- related problems, where redness of eye, eye itching, eye irritation, lacrimation and deep pain in eyes was $66.8 \%$ (141), 73.5\% (155), 45.9\% (97), 57.3\% (121) and 52.6\% (111) respectively.

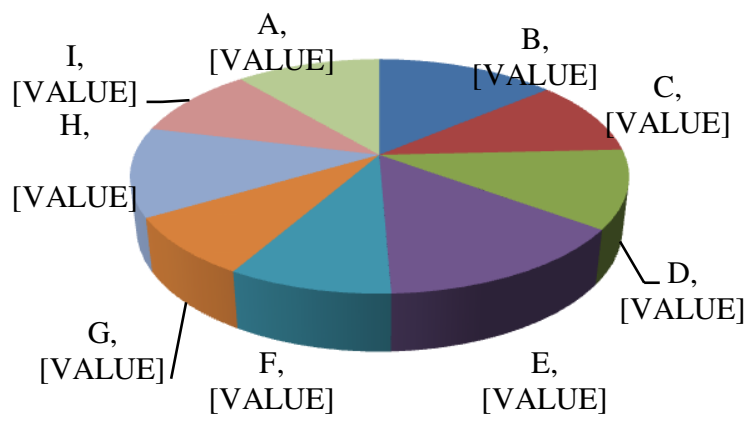

Fig. 7 Different types of health hazards; A. Swallowing accounts 105; B. Coughing, 130; C. Wheezing, 97; D. Shortness of breath, 101; E. Sneezing, 134; F. Nausea, 84; G. Vomiting, 77; H. Headache, 115; I. Sinus, 93.

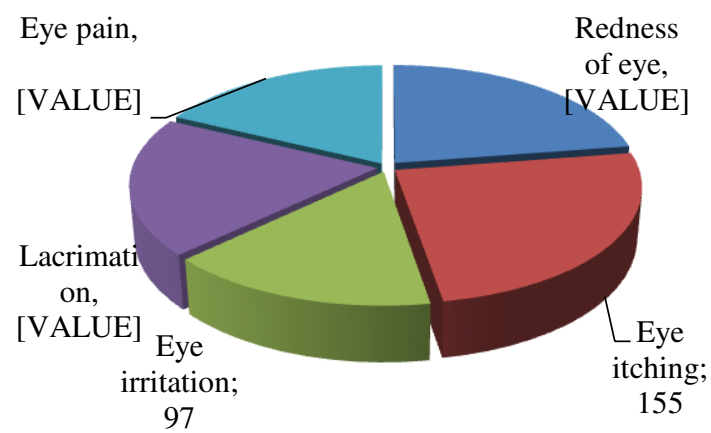

Fig. 8 Different types of eye-related health hazards.

The surveyed illustrations that among the 204 teachers and 58 students, $44.1 \%$ of teachers and $50 \%$ of the students consulted various specialists. From the analysis, it is seen that $60.3 \%$ among the whole respondents visited occultist. Besides the eye specialists, the patients also visited medicine, skin, ENT specialists by $6.9 \%, 4.1 \%, 5.8 \%$, respectively. Among the whole population, around $45 \%$ of respondents did not face any significant problems to consult a doctor.

\subsection{Chalk fabrication}

In order to find out the optimum proportions of raw materials and binders, a series of experiments were carried out to check the attributes of eco-chalk, are summarized in Table 1. From the table, it is seen that the visibility of chalk was low when the different proportion of calcium sulfate and calcium carbonate were mixed with a fixed amount (1.5 ml) of 
Vol. 6, Issue 11, November 2019

white glue. Visibility of chalk was found the same for different proportions of paper gum. However, using Fast ${ }^{\circledR}$ as a binder results in a satisfactory level of visibility. Table 2 shows the visibility test results for various combinations of raw materials and binder including white glue. From the visibility viewpoint, Table 2 shows better results than Table 1 . In this case, white glue of varying proportion $(0.5$ and $1.0 \mathrm{ml})$ were mixed with different fractions of calcium sulfate and calcium carbonate. From the results, it is found that chalks with $0.5 \mathrm{ml}$ white glue showed better visibility than chalks with $1.0 \mathrm{ml}$ white glue. The chalks with the highest visibility and erasability were then needed for their dust production. Results obtained from the test are shown in Table 3 and 4 . From the table, it is found that sample 15 and 17 produce the least amount of dust. From Table 2-4, it can be concluded that chalks with 3.0-6.0 ml of calcium sulfate and $9.0-12.0 \mathrm{ml}$ of calcium carbonate, and $0.5 \mathrm{ml}$ of white glue provide their optimal performance in terms of visibility, erasability, and dust production.

\subsection{Microscopic analysis}

After checking the visibility, erasability, and dust content, the microstructures of the chalk-marks were tested focusing on a specified area along the draw path. These microscopic-views were scrutinized based on particles in the captured area. The microscopic images of various chalk samples are illustrated in Fig. 9.

Table 1 Analysis of visibility and hardness based on raw materials and binder properties

\begin{tabular}{lcccccccc}
\hline Sample no. & $\begin{array}{c}\text { Calcium } \\
\text { sulfate }(\mathrm{ml})\end{array}$ & $\begin{array}{c}\text { Calcium } \\
\text { carbonate }(\mathrm{ml})\end{array}$ & $\begin{array}{c}\text { White } \\
\text { glue }(\mathrm{ml})\end{array}$ & $\begin{array}{c}\text { Fast }^{\circledR} \\
(\mathrm{ml})\end{array}$ & $\begin{array}{c}\text { Paper gum } \\
(\mathrm{ml})\end{array}$ & $\begin{array}{c}\text { Setting time } \\
(\mathrm{min})\end{array}$ & Visibility & Hardness \\
\hline Sample 1 & 3.0 & 12 & 1.5 & - & - & 15 & 1 & Hard \\
Sample 2 & 4.5 & 10.5 & 1.5 & - & - & 15 & 2 & Hard \\
Sample 3 & 6.0 & 9.0 & 1.5 & - & - & 20 & 2 & Hard \\
Sample 4 & 7.5 & 7.5 & 1.5 & - & - & 15 & 2 & Hard \\
Sample 5 & 7.5 & 7.5 & 2 & - & - & 15 & 1 & Hard \\
Sample 6 & 9.0 & 6.0 & 1.5 & - & - & 20 & 1 & Hard \\
Sample 7 & 10.5 & 4.5 & 1.5 & - & - & 10 & 2 & Hard \\
Sample 8 & 9.0 & 6.0 & - & 2.0 & - & 10 & 4 & Powder \\
Sample 9 & 9.0 & 6.0 & - & 2.5 & - & 3 & Hard \\
Sample 10 & 6.0 & 9.0 & - & - & - & 5 & 20 & Hard \\
Sample 11 & 7.5 & 7.5 & - & - & 5 & & Powder \\
\hline
\end{tabular}

Table 2 Analysis of visibility and hardness based on raw materials and binder properties

\begin{tabular}{lccccccc}
\hline Sample no. & $\begin{array}{c}\text { Calcium } \\
\text { sulfate }(\mathrm{ml})\end{array}$ & $\begin{array}{c}\text { Calcium } \\
\text { carbonate }(\mathrm{ml})\end{array}$ & $\begin{array}{c}\text { White glue } \\
(\mathrm{ml})\end{array}$ & $\begin{array}{c}\text { Water } \\
(\mathrm{ml})\end{array}$ & $\begin{array}{c}\text { Temperature } \\
\left({ }^{\circ} \mathrm{C}\right)\end{array}$ & $\begin{array}{c}\text { Setting time } \\
(\mathrm{min})\end{array}$ & Visibility \\
\hline Sample 12 & 3.0 & 12.0 & 1.0 & 8.0 & Med & 15 & 4 \\
Sample 13 & 3.0 & 12.0 & 0.5 & 7.5 & Med & 15 & 5 \\
Sample 14 & 4.5 & 10.5 & 1.0 & 7.0 & Med & 15 & 4 \\
Sample 15 & 4.5 & 10.5 & 0.5 & 8.0 & Med & 15 & 5 \\
Sample 16 & 6.0 & 9.0 & 1.0 & 7.0 & Med & 15 & 4 \\
Sample 17 & 6.0 & 9.0 & 0.5 & 7.5 & Med & 15 & 5 \\
Sample 18 & 7.5 & 7.5 & 1.0 & 7.5 & Med & 15 & 5 \\
\hline
\end{tabular}

Table 3 Analysis of erasability based on raw materials and binder properties

\begin{tabular}{|c|c|c|c|c|c|c|c|}
\hline Sample no. & $\begin{array}{c}\text { Calcium sulfate } \\
(\mathrm{ml})\end{array}$ & $\begin{array}{c}\text { Calcium } \\
\text { carbonate }(\mathrm{ml}) \\
\end{array}$ & $\begin{array}{l}\text { White glue } \\
(\mathrm{ml})\end{array}$ & Fast (ml) & $\begin{array}{c}\text { Paper gum } \\
(\mathrm{ml})\end{array}$ & $\begin{array}{c}\text { Setting } \\
\text { time }(\mathrm{min}) \\
\end{array}$ & Erasability \\
\hline Sample 9 & 9.0 & 6.0 & - & 2.5 & - & 10 & 3 \\
\hline Sample 10 & 6.0 & 9.0 & - & - & 3 & 20 & 5 \\
\hline Sample 12 & 3.0 & 12 & 1.0 & - & - & 15 & 4 \\
\hline Sample 13 & 3.0 & 12 & 0.5 & - & - & 15 & 5 \\
\hline Sample 14 & 4.5 & 10.5 & 1.0 & - & - & 15 & 4 \\
\hline Sample 15 & 4.5 & 10.5 & 0.5 & - & - & 15 & 5 \\
\hline Sample 16 & 6.0 & 9.0 & 1.0 & - & - & 15 & 4 \\
\hline Sample 17 & 6.0 & 9.0 & 0.5 & - & - & 15 & 5 \\
\hline Sample 18 & 7.5 & 7.5 & 1.0 & - & - & 15 & 5 \\
\hline
\end{tabular}




\section{International Advanced Research Journal in Science, Engineering and Technology}

Vol. 6, Issue 11, November 2019

Table 4 Analysis of dust production based on raw materials and binder properties

\begin{tabular}{|c|c|c|c|c|c|c|c|}
\hline Sample no. & $\begin{array}{l}\text { Calcium sulfate } \\
(\mathrm{ml})\end{array}$ & $\begin{array}{c}\text { Calcium } \\
\text { carbonate }(\mathrm{ml})\end{array}$ & $\begin{array}{c}\text { White } \\
\text { glue }(\mathrm{ml})\end{array}$ & $\begin{array}{l}\text { Fast } \\
(\mathrm{ml})\end{array}$ & $\begin{array}{l}\text { Paper gum } \\
(\mathrm{ml})\end{array}$ & $\begin{array}{l}\text { Setting time } \\
(\mathrm{min})\end{array}$ & Dust \\
\hline Sample 9 & 9 & 6 & - & 2.5 & - & 10 & 4 \\
\hline Sample 10 & 6 & 9 & - & - & 3 & 20 & 1 \\
\hline Sample 13 & 3 & 12 & 1 & - & - & 15 & 3 \\
\hline Sample 15 & 4.5 & 10.5 & 0.5 & - & - & 15 & 1 \\
\hline Sample 16 & 6 & 9 & 1 & - & - & 15 & 5 \\
\hline Sample 17 & 6 & 9 & 0.5 & - & - & 15 & 1 \\
\hline Sample 18 & 7.5 & 7.5 & 1 & - & - & 15 & 4 \\
\hline
\end{tabular}

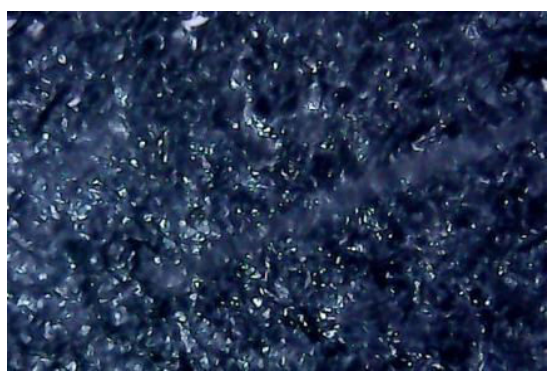

(a) Sample no. 5

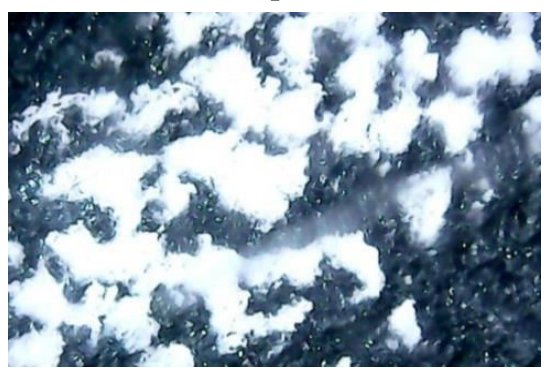

(a) Sample no. 13

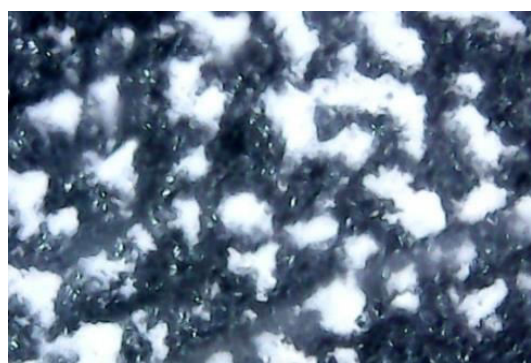

(b) Sample no. 9

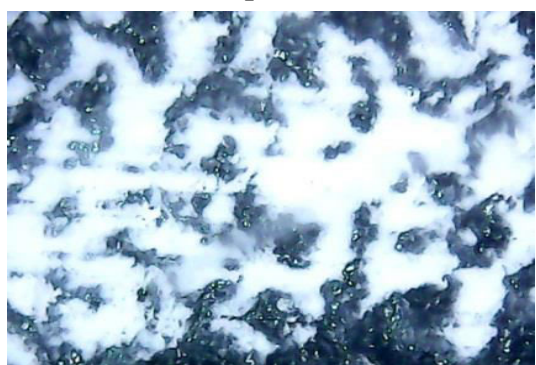

(b) Sample no. 15

Fig. 9 Microscopic images of the fabricated chalk marks for different tested samples.

From these microscopic views, it was observed that some chalk marks contained more dense chalk particles than others. The more density on chalk marks indicates the more of consumption during writing. On the contrary, chalk marks having comparatively higher density provides better visibility and more dust production. From this phenomenon, it can be concluded that if two chalk marks of the same visibility are compared with one another, then chalk mark having less density is better than chalk mark having higher density. This is due to the fact that the chalk marks for same visibility, the higher density consumes more the chalk particles and vice versa. A constant amount of this particle contributes to the visibility and rest produces dust. If the density of the chalk particle is too low, it may not produce a mark of good visibility (Fig. 9(a)). In the microstructure of sample 5, 7.5 ml of calcium sulfate, and the same amount of calcium carbonate and $2.0 \mathrm{ml}$ white glue was used. As a result, the sample chalk did not create any significant mark on the board, i.e., the visibility was very poor. Fig. 9(b) shows the microstructure of the sample 9 chalk where $9.0 \mathrm{ml}$ of calcium sulfate $6.0 \mathrm{ml}$ of calcium carbonate and $2.5 \mathrm{ml}$ white glue (Fast $\AA$ ) was used. The sample chalk was hard enough, but ultimately erasability is less than others. Sample 13, shown in Fig. 9(c), was composed of $3.0 \mathrm{ml}$ calcium sulfate, $12.0 \mathrm{ml}$ of calcium carbonate and $0.5 \mathrm{ml}$ white glue, had the best quality in the sense of visibility, erasability, and medium in the sense of dust content. Again, Fig. 9(d) for the sample 15, composed of 4.5 ml of calcium sulfate $10.5 \mathrm{ml}$ of calcium carbonate and $0.5 \mathrm{ml}$ white glue, created maximum visibility, maximum erasability, and produces the least amount of dust. That is why Sample 15 stood the highest rank than others.

\section{DISCUSSION}

From this work, it can be inferred that among the total respondents, there was $70.3 \%$ of teachers, $20 \%$ of students and $9.7 \%$ guardians. The reason for selecting a higher number of teachers than students as teachers are the direct user of chalk, and they inhale a more significant portion of chalk dust during wiped from the blackboard as well. The percentage of guardians was less because of the only representative of those students who were unable to put a mark on 


\title{
International Advanced Research Journal in Science, Engineering and Technology
}

\author{
Vol. 6, Issue 11, November 2019
}

questionnaire, i.e., mostly pre-primary students. It is anticipated that most of the government schools still use chalk as a teaching medium. In primary schools and high schools, about $70 \%$ of teachers use only chalk, and the rest use chalk with another available medium. Therefore, it can be concluded that chalk is still a famous teaching medium among teachers. As a significant percentage of teachers use dry eraser maker (Fig. 2 and 4), it does not mean that the teachers are always using dry eraser marker in the classroom instead of chalk. Rather they use marker personally when they taught their students at home or coaching center. About $63.69 \%$ teacher prefer round nib than the chisel nib marker. Refereeing to Fig. 3, the teachers who use chalk asked for a cover on chalk to avoid direct contact of chalk powder. This is because many teachers have an allergic problem, and besides, they do not feel comfortable while gripping the chalk surface. This chalk cover also reduces the early breakage problem of chalk, and the cover helps in gripping. Considering all the merits and demerits of chalk covers, it can be deduced that paper is a convenient medium of chalk cover $(26.88 \%$ preferred paper) that will be the best among all other alternatives. It is ease of unwrapping, and it is user-friendly too. A significant percent (30.11\%) preferred rubber as it is soft, comfortable when gripping the chalk. As a cover, cotton is less favorable than others as cotton is problematic for unpacking, and therefore, only $2.69 \%$ of teachers preferred the cotton. While writing and scraping on the blackboard, the chalk sticks a massive number of suspended particles, including coarse and fine chalk powders. Because of the concentration gradient, the concentration of fine particles gradually increases from the chalkboard area toward the student seating area. After turning on the ceiling fan, the suspended chalk powders spread around the classroom and introduced into the human respiratory system and reach the lung alveoli. Moreover, the students who particularly seat nearby the blackboard are exposed much from the chalk dusts. During teaching, the chalk dusts enter the respiratory system through the nasopharyngeal region and mouth could be extensive in teachers due to the proximity to the blackboard and frequent opening the mouth to deliver lectures and heavier breathing due to exhaustion. As the internal tissues are soft and sensitive, inhaling chalkdusts causes respiratory inflammation, and sometimes pulmonary ventilation function is reduced, and its results coughing, wheezing, sneezing, nausea, and vomiting. The shortness in breath causes less amount of oxygen supply causes sinus, swallowing, and headache. Among the health-related problems, besides the respiratory system related problems, allergy, eye, skin and hair-related problems are most common. The chalk dusts fall into the eyes, affects the lachrymal gland, constitutes mucosa damage which constitute a slow inflammation, can cause the onset of myopia. The dusts also fall on the skin, hair, face to neck, sometimes dissolved into the sweat solution, make the skin dry, rough, and accompanied by itching feeling. The particles accumulated on the hair make the hair rough; the result is itching and hair fall. From the study, it is observed that a good number of guardians discuss their children's health problems with school teachers and the frequency is more than 90 percent. It is also seen that most of them need a consultation by doctors, and among the chalk users more than 60 percent is teacher, and the rest are students. Therefore, it can be concluded that the guardians are conscious about their children's health. Sometimes the chalk users need to consult with various specialists. The maximum problem accounted is the eye-related problem, and about 60 percent among the respondents visited occultist. The respondents who were consulted by medicine, skin, ENT and child specialist are not rare. Excepts accumulated in or on the human body, rest of the dusts enter into different classroom equipment, settled down on school bags, shoes, books, etc. About 82 percent guardians claims that their children's' clothes were spoiled because of chalk dust. We can conclude from the table that teachers were more sufferer than students as their clothes become filthier. From Table 1, it is seen that visibility is very less except sample 8 and 9 where 2.0 to 2.5 ml Fast ${ }^{\circledR}$ binder are used with $9.0 \mathrm{ml}$ calcium sulfate and $6.0 \mathrm{ml}$ of calcium carbonate. But, after mixing and curing, sample 8 is in a powder state, therefore, it is discarded. In other cases, visibility is very low for paper gum. This is because of very weak material bonding. If more gum is added, the percentage of gum will increase, which made the paste stickier. As a result, good quality of chalk can never be produced with this combination. So, paper gum was discarded as a binder. From Table 2, the chalks which confirm most visibility are sample 13,15, 17, and 18, these are mostly selected for erasability test. The test of visibility is the first test because the other tests become worthless if the chalk does not show proper visibility. After visibility, the second test is the erasibility. For this reason, the chalks with least visibility are discarded and then the erasability test was carried out. This is a complete visual inspection. The chalk which do not pass in the erasibility test cannot move forward for dust production (least volume of dust) test. But before the dust production test, visibility and erasability must be ensured. Therefore, it can be deduced from Table 4, sample 15 and 17 are the best quality chalks where white glue of varying proportions 0.5 to 1.0 with a mixture of 4.5 to $6.0 \mathrm{ml}$ of calcium sulfate and 9.0 to $12.0 \mathrm{ml}$ of calcium carbonate are used.

\section{CONCLUSION}

In this study, a survey was carried out, and the analysis of data was done according to the response on research a questionnaire was developed based on the objectives of the study. The following conclusions were derived from the study. According to the survey, all government-funded primary and high schools are till now using chalk as a teaching medium. In these schools, the uses of the modern technology were rare and sometimes absent. In primary and high schools, about $70 \%$ of teachers use only chalk, and the rest use chalk with another available medium. Color chalk was a requirement of the respondents. Most of the teachers and students selected pink color. The percentage of teachers who 


\title{
International Advanced Research Journal in Science, Engineering and Technology
}

\author{
Vol. 6, Issue 11, November 2019
}

chose green and red color was also noteworthy. However, respondents preferred covered chalk, and as a cover, they had chosen paper, rubber and plastic paper, etc. The dusts coming from the chalkboards are very much harmful to the respiratory system, skins body and eyes. The chalkdusts enter the respiratory system through the nasopharyngeal region and mouth severely affects the respiratory and pulmonary system causes coughing, wheezing, sneezing, nausea, vomiting, sinus, swallowing, and headache problems. Not only the human respiratory system but also different classroom equipments are affected by the chalkdusts. The performance evaluation of designed and fabricated ecofriendly chalk was carried out using a different proportion of calcium carbonate, calcium sulfate, binder, and water. If the percentage of calcium sulfate is increased, the percentage of water also increases. The percentage of calcium sulfate should not be more than percentage of the calcium carbonate. The eco-friendly dustless chalk is made of materials, wherein the primary materials comprise the following components in percentage by volume: $32-50 \%$ of calcium carbonate precipitated, $12-32 \%$ calcium sulfate di-hydrate, $4.1-4.3 \%$ of binder and $31-33 \%$ of water. The obtained dustless chalk is the desired chalk for smooth writing, in the sense of visibility, erasability, and dust content. Moreover, the chalk components are low cost, and readily available. The obtained dustless chalk was excellent and flexible in quality, smooth in writing, clear in writing and bright color, furthermore, the fabricated chalks do not break easily during write up, made from easily obtainable raw materials and equipment used for production are comparatively less expensive, and most important of all, less dust produces in writing and erasing processes.

\section{ACKNOWLEDGMENT}

This work was carried out in the Department of Industrial \& Production Engineering, Shahjalal University of Science $\&$ Technology, Sylhet, Bangladesh. Authors are grateful to all the teachers, students, guardians who participated in the survey.

\section{REFERENCES}

[1]. N. Schlager, How products are made: an illustrated guide to product manufacturing, Gale Research Inc., United Kingdom, 1994.

[2]. S.A. Meo, S. Shahabuddin, A. A. Al Masri, et al., "Comparison of the impact of PowerPoint and chalkboard in undergraduate medical teaching: An evidence based study," Journal of the College of Physicians and Surgeons Pakistan. vol. 23(1), pp. 47-50, 2013.

[3]. S. R. Kewate, V. R. Gandhewar, S. V. Thorat and H. R. Pant, "Development of intelligent type design to escape the chalk dust from the duster eraser used for classroom blackboard in Schools/ Colleges," IOSR Journal of Mechanical and Civil Engineering, pp. 32-36, 2014.

[4]. S. Waheeda and K. S. Murthy, "A comparative study of blackboard teaching with PowerPoint teaching in 1year medical students," National Journal of Basic Medical Sciences, vol. 6(1), pp. 11-13, 2015.

[5]. S. N. Bamne and A. S. Bamne, "Comparative study of chalkboard teaching over PowerPoint teaching as a teaching tool in undergraduate medical teaching,” International Journal of Medical Science and Public Health, vol. 5(12), pp. 2585-2587, 2016.

[6]. M. Rohatgi, "A dust-free chalk for teachers," Technology Review, vol. 2(10), pp. 70, 2010.

[7]. M. Jaishankar T. Tseten, N. Anbalagan, et al., "Toxicity, mechanism and health effects of some heavy metals," Interdisciplinary Toxicology, vol. 7(2), pp. 60-72, 2014.

[8]. B. O. Anyanwu, A. N. Ezejiofor, Z. N. Igweze and O. E. Orisakwe, "Heavy metal mixture exposure and effects in developing nations: An update," Toxics, vol. 6, pp. 65-96, 2018.

[9]. L. Järup, "Hazards of heavy metal contamination," British Medical Bulletin, vol. 68, pp. 167-182, 2003.

[10]. P. B. Tchounwou, C. G. Yedjou, A. K. Patlolla, and D. J. Sutton, "Heavy metals toxicity and the environment," Experientia supplementum, vol. 101, pp.133-164, 2012.

[11]. B. D. Bołzan, "Effect of heavy metals on living organisms," World Scientific News, vol. 5, pp. 26-34, 2014

[12]. C.C.Lin, M.K.Lee \& H.L.Huang, "Effects of chalk use on dust exposure \& classroom air quality," Aerosol \& Air Quality Res, vol.15, 2015.

[13]. G. Du-Toit, "Clinical allergy images," Current Allergy and Clinical Immunology, vol. 18(3), pp. 148-150, 2005.

[14]. Z. Á. Szász1, E. Székely-Vass, G. Horváth and M. Hozoi, "Chalk-induced lung fibrosis-Case report,” Journal of Interdisciplinary Medicine. Vol. 2(4), pp. 357-361, 2017.

[15]. S. B. Chandanshiv, P. D. Patil, P. U. Chavan, K. J. Bachhav and H. V. Choudhari, "Study on effect of chalk dust on class room environment \& on human body and new development to clean chalk board," International Journal of Management, Technology and Engineering, vol.8(9), pp.421-426, 2018.

[16]. T. Daniels, Chalk it up to experience, Iowa State Daily.Com, 21th October, 2004, Access on: 10 Apr, 2019, Available in: http://www.iowastatedaily.com/article_66c5a6a1-ce24-5c98-a2ce-09478d2f4750.html (accessed 10 April 2019).

[17]. M. Muthoni, Factors associated with occupational allergic conjunctivitis among school teachers in Bahati Division, Nakuru North District, Kenya, Master's thesis, Kenyatta University, 2011.

[18]. Y. A. Maruthi, S. Ramprasad and N. L. Das, "Trace elemental characterization of chalk dust and their associated health risk assessment," Biological Trace Element Research, vol. 175(2), pp. 466-474, 2017.

[19]. K. D. Nikam and A. H. Munira, "Effects of chalk dust on peak expiratory flow rate in school teachers," International Journal of Medical and Health Science, vol. 2(4), pp. 407-409, 2013.

[20]. M. Pollick, Is chalk harmful? wiseGEEK features. Conjecture Corporation. Available in: https://www.wisegeek.com/is-chalk-dust-harmful.htm (accessed on 10 April, 2019).

[21]. S. Ashok, Eye allergies, in Kumar, R. and Kumar, M. (Eds). Guide to allergies and their cure, Prevention and treatment. Deep and Deep Publications, New Delhi, pp. 67-72, 2003.

[22]. G. Volans and H. Wiseman, Drugs Handbook (rev. ed.). Bristol: Palgrave Macmillan, 2005.

[23]. S. J. Hung, "Comparing the legibility of different coloured chalk in teaching on a blackboard," World Transactions on Engineering and Technology Education, vol. 14(3), pp. 333-340, 2016.

[24]. P. D‘Arienzo, Allergic disease therapies key to patient quality of life, Ophthalmology Times Special Reports. 2005.

[25]. S. J. Ono and M. B. Abelson, "Allergic conjunctivitis update on pathophysiology and prospects for future treatment," Allergy in Clinical Immunology, vol. 115(1), pp. 118-122, 2005.

[26]. N. Ait-Khaled, J. Odhiambo, N. Pearce, et al., "Prevalence of symptoms of asthma, rhinitis and eczema in 13- to 14-year-old children in Africa," The International Study of Asthma and Allergies in Childhood Phase III. Allergy, vol. 62(3), pp. 247-258, 2007. 